\title{
Research Paper: Impact of Air Seat Cushions and Ball Chairs on Classroom Behavior of Students with Autism Spectrum Disorder
}

\author{
Nader Matin Sadr ${ }^{1}$, ${ }^{*}$ Hojjat Allah Haghgoo ${ }^{1}$, Sayyed Ali Samadi ${ }^{2}$, Mehdi Rassafiani ${ }^{1}$, Enayatollah Bakhshi ${ }^{3}$
}

1. Department of Occupational Therapy, University of Social Welfare and Rehabilitation Sciences, Tehran, Iran.

2. Center for Intellectual and Developmental Disabilities, Institute of Nursing and Health Research, University of Ulster, Northern Ireland.

3. Department of Biostatistics, University of Social Welfare and Rehabilitation Sciences, Tehran, Iran.

Citation: Matin Sadr N, Haghgoo HA, Samadi SA, Rassafiani M, Bakhshi E. [Impact of Air Seat Cushions and Ball Chairs on Classroom Behavior of Students with Autism Spectrum Disorder (Persian)]. Journal of Rehabilitation. 2016; 17(2):136-147. http://dx.crossref.org/ 10.21859/jrehab-1702136

http://dx.crossref.org/ 10.21859/jrehab-1702136

Received: 06 Feb. 2016 Accepted: 25 Apr. 2016

\begin{abstract}
Objective Children with Autism Spectrum Disorder (ASD) have a lot of sensory integration problems, which severly interfere with their learning process in the classroom; therefore, they confront with difficult problems in academic achievements. As a result, they need environmental modification to resolve sensory seeking behaviors and improve their educational success. Considering the effects of sensory stimulation and integration in children with ASD, this study aimed to examine the impacts of sitting on a ball, cushion, and or common chair on classroom behavior of 4 students with ASD. Because alternative seating like therapy balls and air cushions instead of regular chairs can exert various sensory stimuli on student's sensory organs, this study aimed to examine the effects of three alternative classroom-seating devices; i.e. regular classroom chairs, therapy balls, and air cushions on students' classroom behaviors. These behaviors include on-seat behavior, on-task behavior, and autistic behavior.
\end{abstract}

Materials \& Methods In this study, 4 male students with ASD in Tabasom Primary School, Mashhad, Iran were investigated in a single-subject study. Their classroom behaviors were recorded and monitored by video recording in an A-B-A-C single-subject design for 4 weeks. Their classroom behaviors were video recorded in 3 phases: Students sat on a normal chair in baseline phases (A), on a cushions in second phase (B), and on a therapy ball in third phase (C). The students' behaviors (including sitting times; in-seat and on-task/ off-task behaviors) were observed and recorded every other day, a session per day, and 10 minutes each session (in total 12 sessions equal to 120 minutes). Sitting times and on-task/off-task behaviors were quantified by momentary time sampling and compared during different phases for important changes. Social validity was taken by the teacher at the end of the research as well. Additionally, the Gilliam Autism Rating Scale - Second Edition test was used to examine stereotyped movements, social and communication skills of the students before and after the research. Social and communication skills of the subjects were evaluated before and after the intervention using The Vineland Social Maturity Scale. Statistical software SPSS version 19 and Excel software were used to analyze the descriptive statistics and drawing diagrams, respectively.

Results The findings of this research demonstrated increases in on-task and in-seat behaviors in 4 students when seated on air sit cushioned chairs and therapy balls when compared to seating on regular chairs. But, despite increase in on-task behaviors for all students, only two of the students showed improved in-seat behaviors when seated on therapy balls. An increase of $11.7 \%$ in on-task behaviors was observed during sitting on a therapy ball, when compared to regular chairs. Furthermore, a $25 \%$ increase was observed in on-task behavior of students when they were seated on air sit cushioned chairs in comparison with regular chairs. The in-seat behaviors were increased by $31.7 \%$ and $23.3 \%$ when sitting on the therapy ball and cushioned air chairs, respectively, when compared with regular chairs. Social validity findings indicated that the teacher preferred the use of the balls and air-cushioned chairs for her students.

Conclusion In the present study, therapy balls and or cushioned chairs for ASD students facilitated in-seat and on-task behaviors and improved classroom performance. It seems that using these alternative seating chairs can satisfy the subjects' needs to sensory stimuli, and therefore, decreases their sensory seeking behaviors which interferes with their academic achievements. While, using therapy ball chairs for these students may facilitate in-seat behavior and decrease autistic behavior in class, the student's response to dynamic seating is different individually. Therefore, chair selection must be based on vestibular reaction of the students.
Keywords:

Autism Spectrum

Disorder, Students,

Sensory Integration

Therapy

\section{* Corresponding Author:}

Hojjat Allah Haghgoo, PhD

Address: Department of Occupational Therapy, University of Social Welfare and Rehabilitation Sciences, Koodakyar Ave., Daneshjoo Blvd., Evin, Tehran, Iran. Tel: +98 (21) 22180037

E-Mail: haghgooh@gmail.com 


\title{
تأثير نشستن روى بالشتكهاى بادى و توب بر رفتار كلاسى دانشآموزان با اختلال طيف اوتيسم
}

\author{
نادر متينصدر'، "حجتالله حقكو'، سيدعلى صمدى'، مهدى رصافيانى'، عنايتالله بخشى'

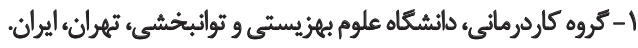

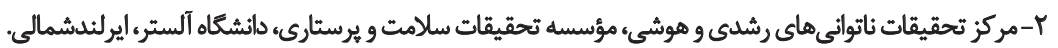

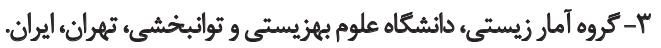

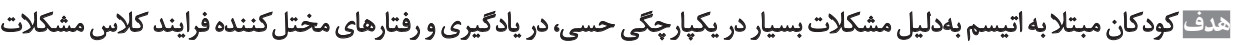

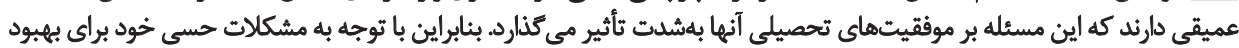

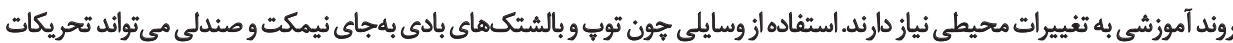

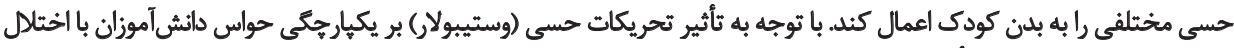

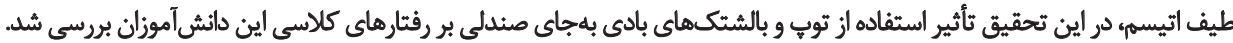

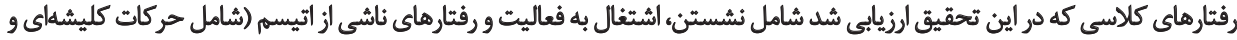

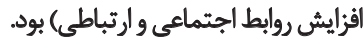

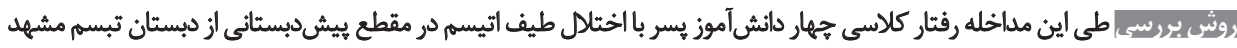

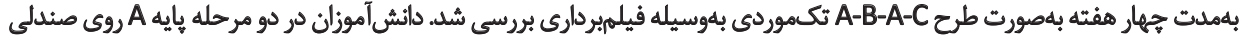

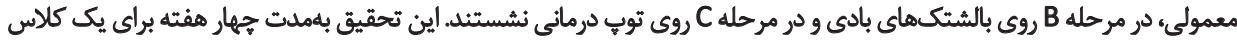

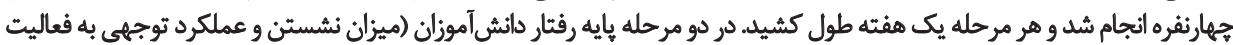

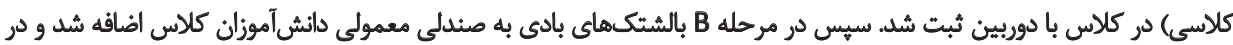

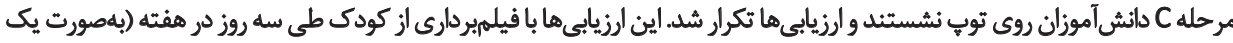

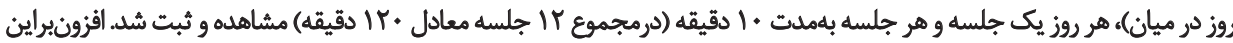

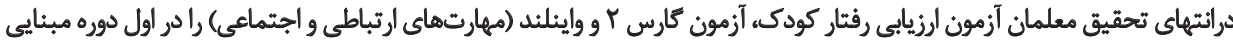

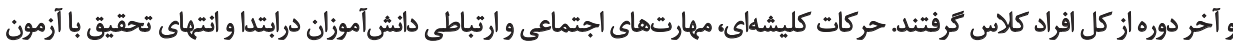

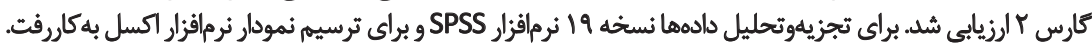

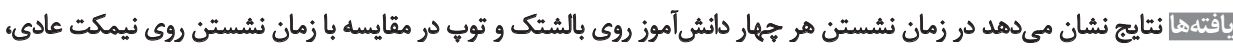

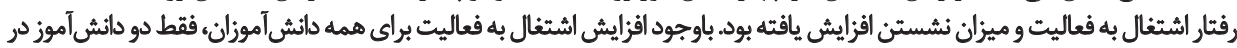

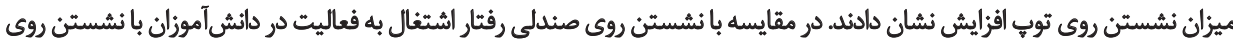

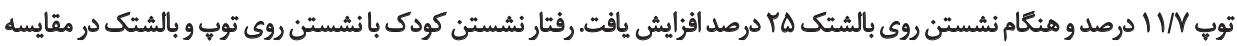

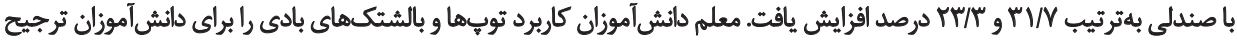

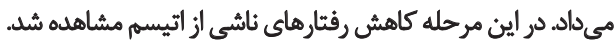

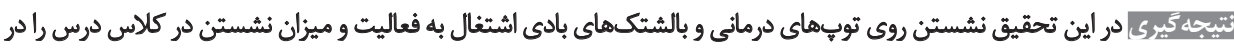

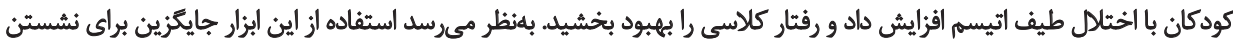

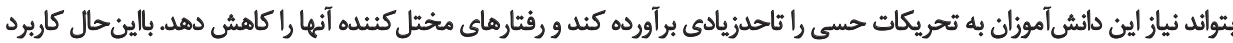

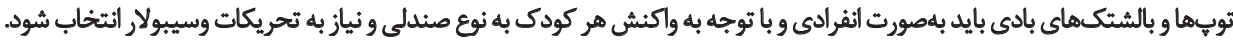


مشاركت دانش آموزان با ناتوائى را در بيى دارد، تأكيد دارند [ـ [1].

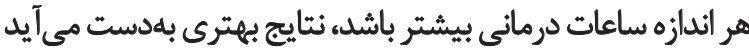

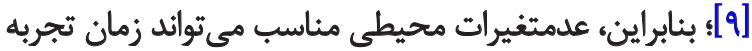

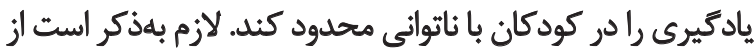

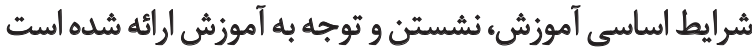

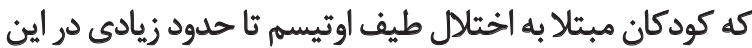

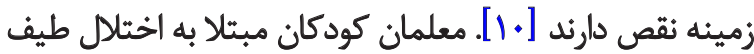

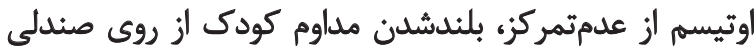

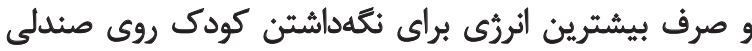

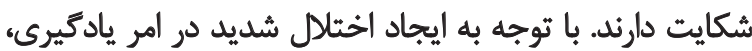

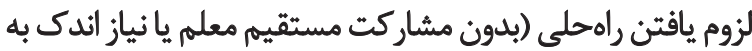

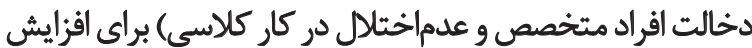

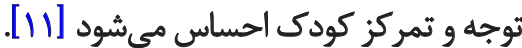

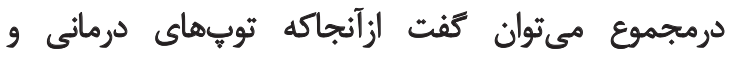

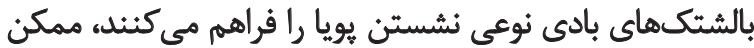

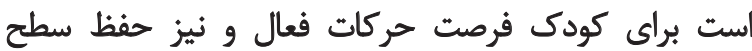

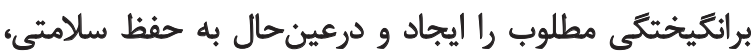

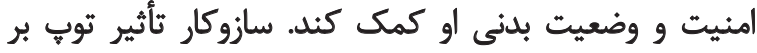

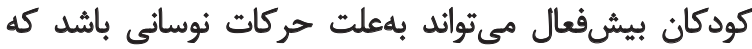

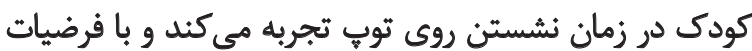

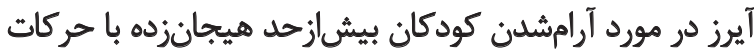

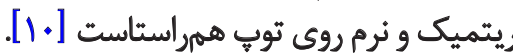

على رغم وجود مشكلات كسترده سطح توجه و حس وستيبولار

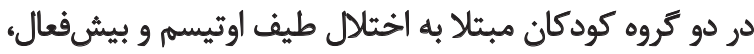

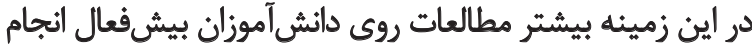

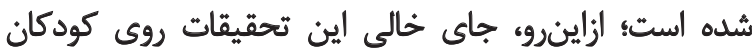

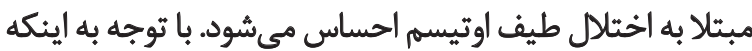

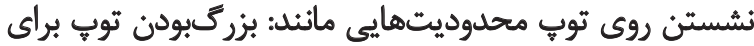

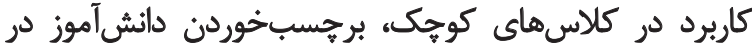

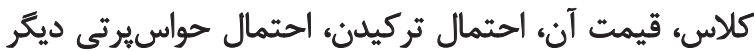

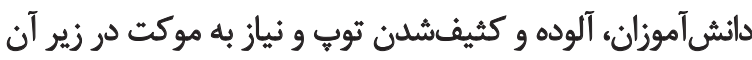

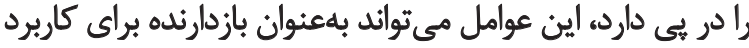

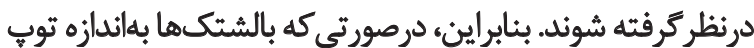

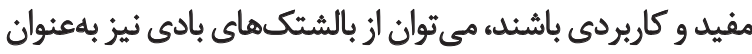

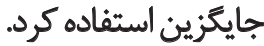

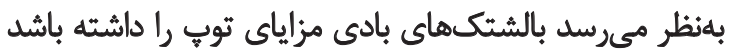

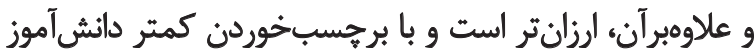

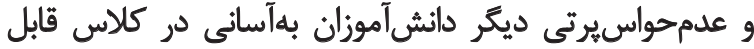

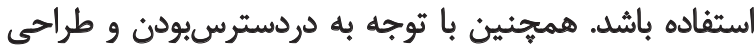

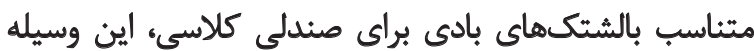

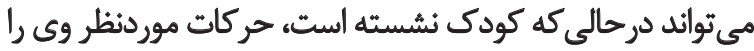

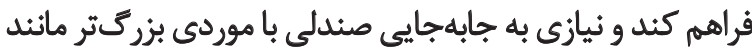

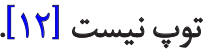

otado

اختلال طيف اوتيسم (ASD)'، حداقل با تأخير يا كاركرد

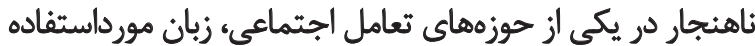

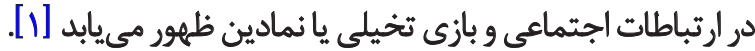

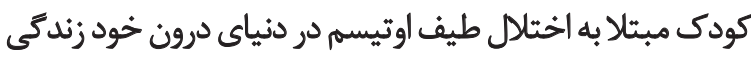

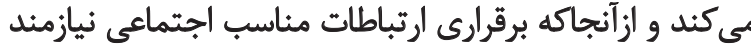

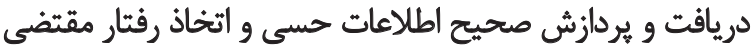

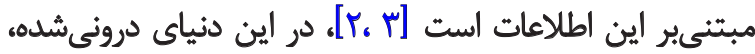

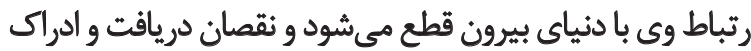

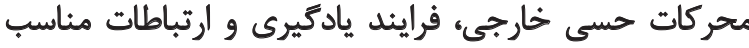

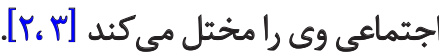

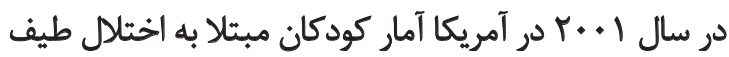

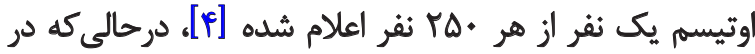

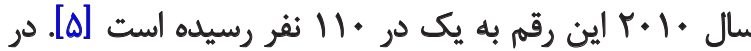

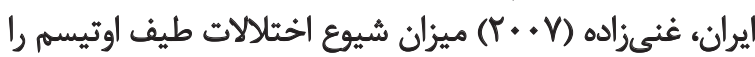

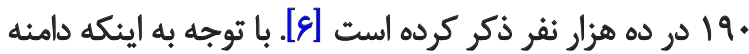

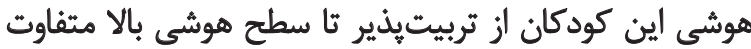

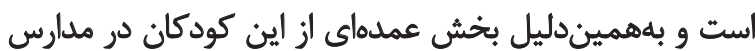

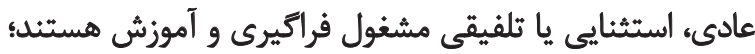
بنابراين، لزوم بررسى موانع و مشكلات آموزشى آنها آنها در سطح

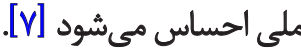

در قرن ال در آمريكا، جمعيت كودكان داراى اختلال طيف

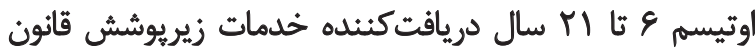

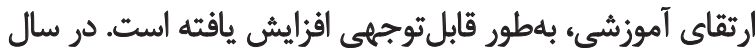

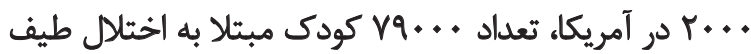

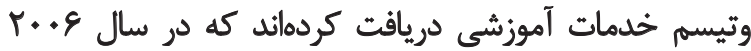

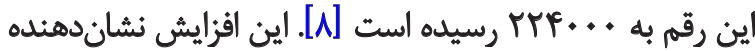

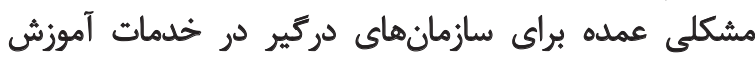

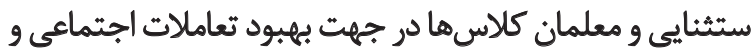
رفتارى كودكان مبتلا به اختلال طيف اوتيسم است [N] ازآنجايىكه رفع هر مانع در يادكيرى به تغييرات محيطى

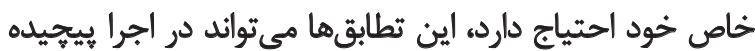

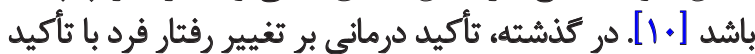

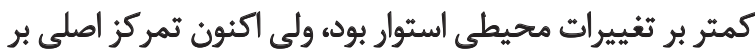

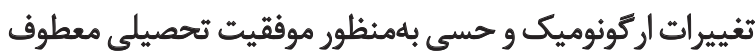

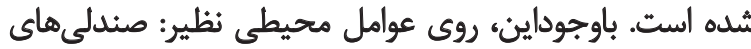
كلاسى و ميزها كه بر يادكيرى دانش آموزان مؤثر است، تحقيط ناسيقات

كمى انجام شده است [.1].

محققان بر كمبود تغييرات محيطى مناسب در كلاسهاى

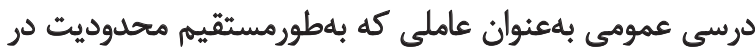

1. Autism Spectrum Disorder (ASD) 


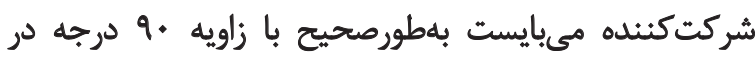

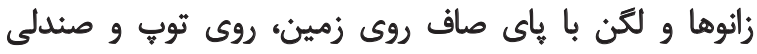

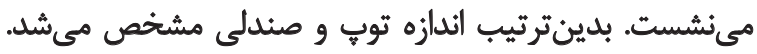

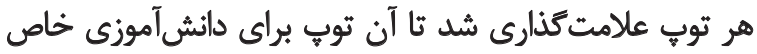

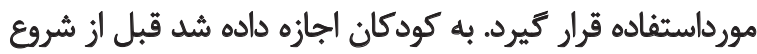

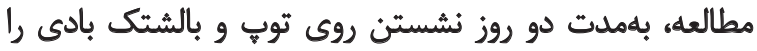

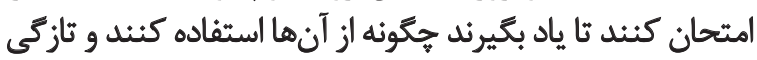
اين ابزار مانع مداخله نشود.

درآغاز بعضى از كودكان براى اثبات خود به راهنمايىهاى

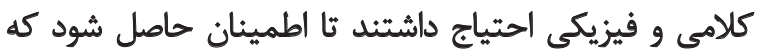

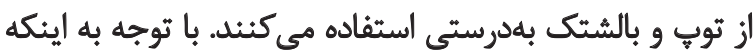

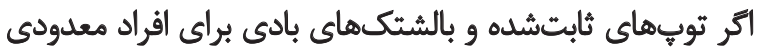

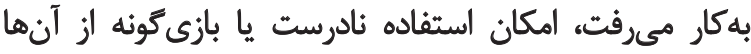

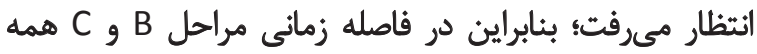

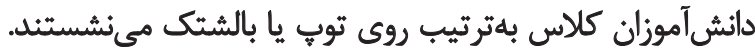

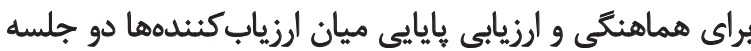
آموزش درنظر كمرفتي شيد.

در طول جهار هفته در كلاس از كودكان فيلم كرفته و در

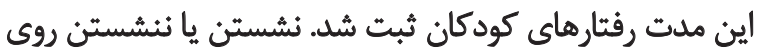

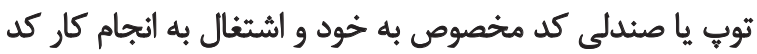

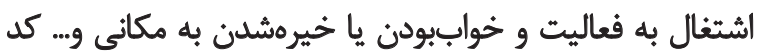

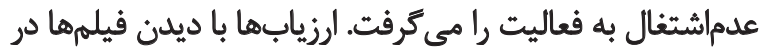

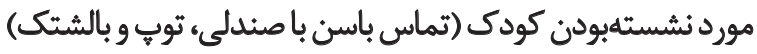
و اشتغال او به فعاليت هدفمند قضاوت مى كردندي

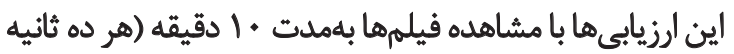

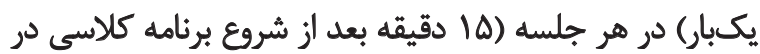

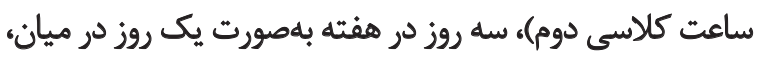

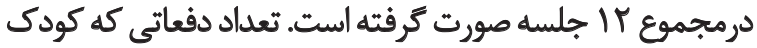
روى توب و بالشتك بادى نشسته و مشغول فعاليت درسئ استى است،

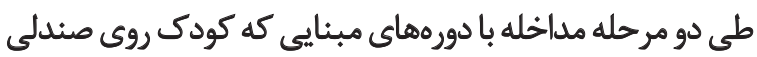

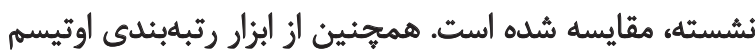

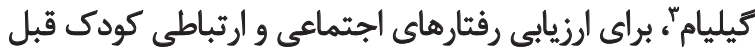

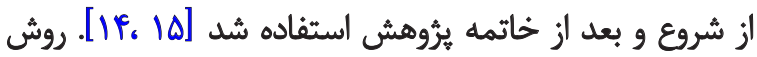

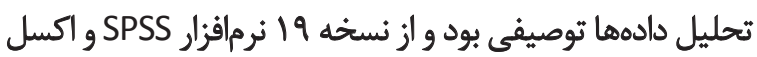

اسفاده شُه است.

يافتهها

رفتارهاي دانشآموزان كلاس طى دو مرحله مداخله كه

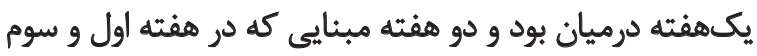

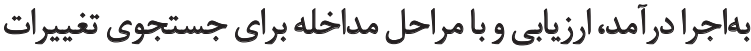

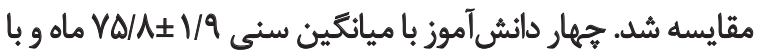

با توجه به آمار روبهافزايش اين دانشآموزان و لزوم ايجاد

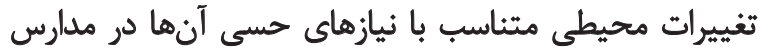
و اينكه تاكنون با جستجوهاى ثرئروهشَّران، مطالعه مشابيه

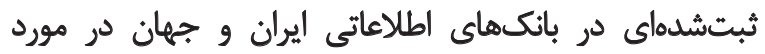

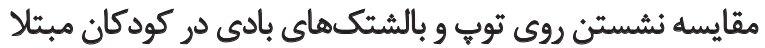

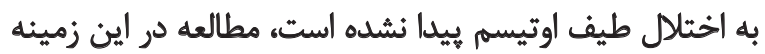

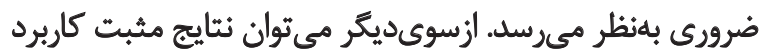

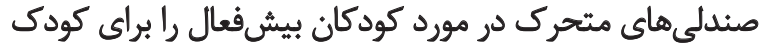

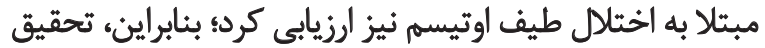

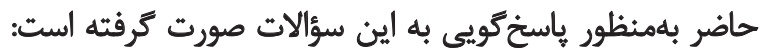

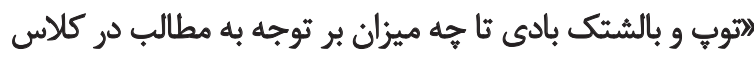

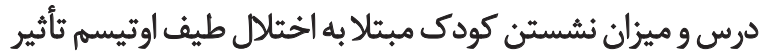

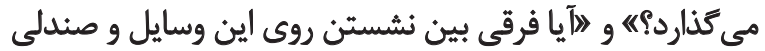

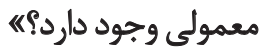
روشُ برورسي جامعه آمارى ثيروهش حاضر را دانشآموزان كلاسهاى

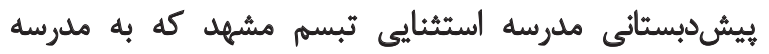

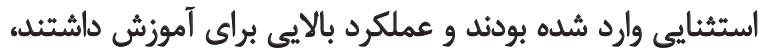

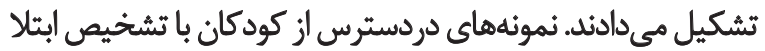

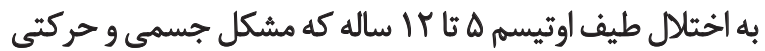

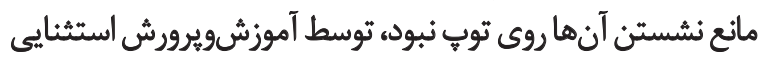

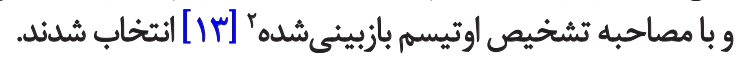
بعد از دريافت اجازه از مؤسسه، والدين دانشآموزان از جريان

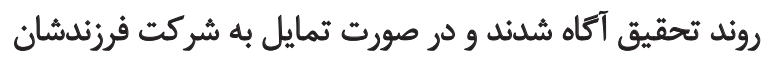

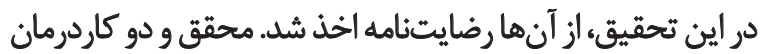

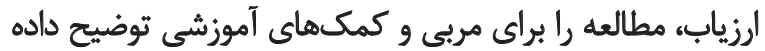

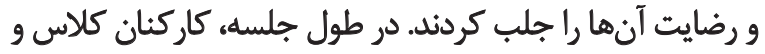

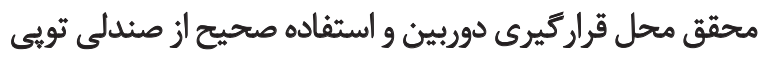
را موردبررسى قرار دادند.

مداخله بهصورت طرح A-B-A-C تكموردى بود كه در مرحله

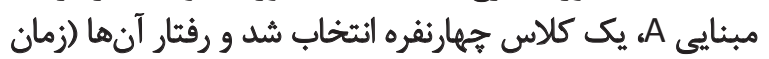

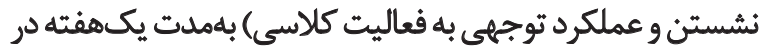

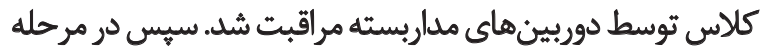

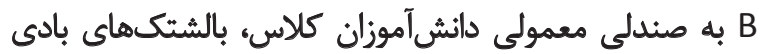

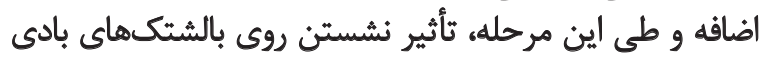

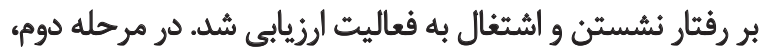
خط بايه ميزان نشستن و اشتغال به فعاليت بارديكر اندازماكيرى

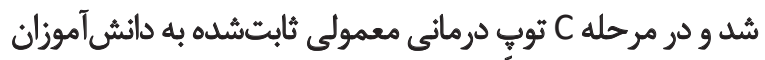

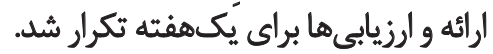
براى تعيين ارتفاع توب و صندلى همراه بالشتكه هر 
جدول (. ميائكين دفعات نشستن، رفتار اشتغال و عدماشتغال به فعاليت دائشآموز اول (بدوناشتغال به فعاليت يا فعاليت بدونهدف).

\begin{tabular}{|c|c|c|c|c|c|c|c|c|}
\hline ميزان كلي عدماشتغال به & موارد & هركات كليشهاى & خيرهُشدن & مرتزنمن & بدون هدف راهرفتن & ميزان أشتغال & نشيزئن & نوع صندلى \\
\hline$\pi$ & 1 & $v$ & & & TA & iv & if & صندلى (A) \\
\hline 1. & $r$ & $r$ & & & 8 & Q. & $m$ & بالشتك (B) \\
\hline r & 1 & $r$ & $r$ & & 17 & mq & $\pi$ & صندلى (AT) \\
\hline 11 & $r$ & & & & 9 & $p q$ & M & (C) \\
\hline
\end{tabular}

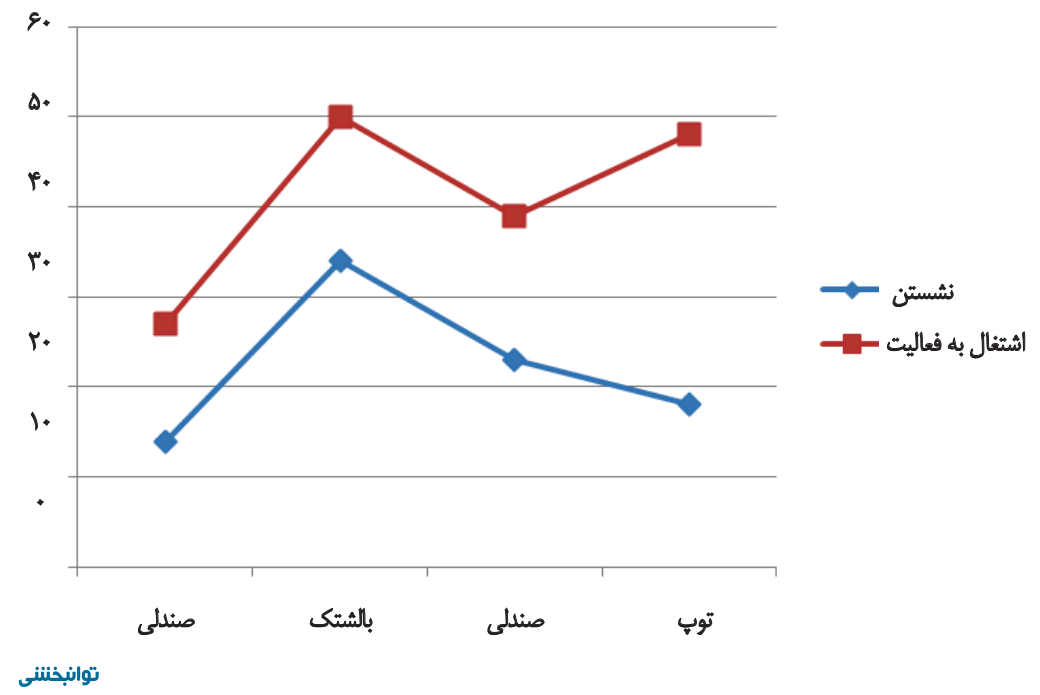

تصوير ا. روند تغييرات ميانكين دفعات نشستن و اشتغال به فعاليت دائشآموز اول در مراحل مختلف تحقيق.

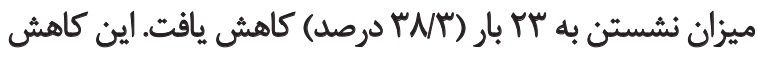

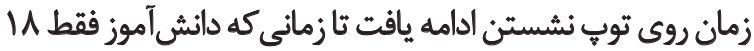
بار (•r درصد) روى توض نشست.

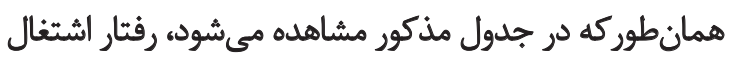

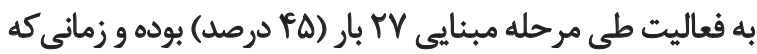

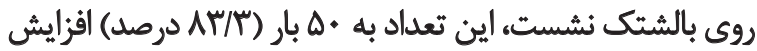

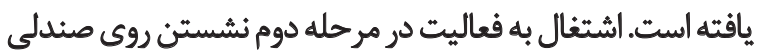

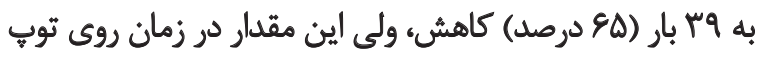

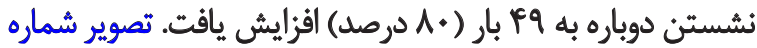
ا روند اين تغييرات رانشان مى دهد.

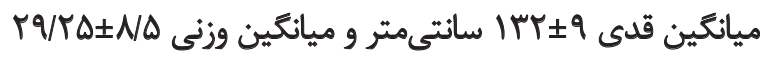

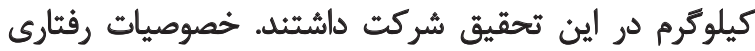

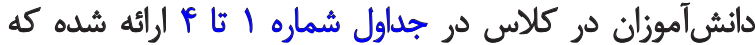

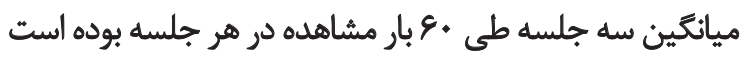

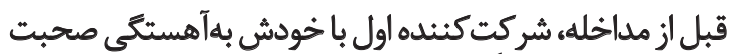

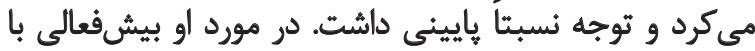

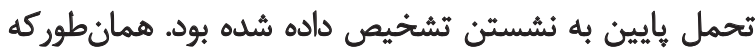

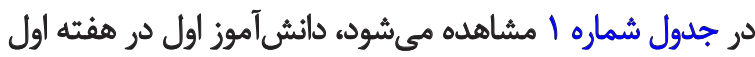

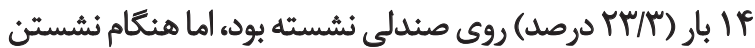

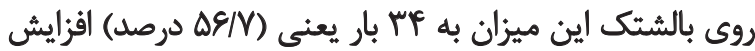

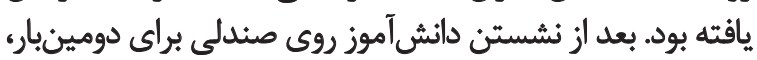

جدول r. ميزان نشستن، رفتار اشتغال و عدماشتغال به فعاليت دانش آموز دوم (بدوناشتغال به فعاليت يا فعاليت بدونهدف).

\begin{tabular}{|c|c|c|c|c|c|c|c|c|}
\hline ميزان كلى عدماثشتغال به & موارد ديكر & حركات كليشهاي & هُيرهشين & هرثزن & بدونهدف بدفن & ميزان أشتغاليت & ميزان نشستن & نوع صندلي \\
\hline re & & 1. & 8 & & 1. & $\pi$ & ar & صندلى (AI) \\
\hline 19 & & 18 & $r$ & & & f. & $\Delta \Delta$ & (B) بالشتك (B) \\
\hline r & & 1. & $\varphi$ & & $\wedge$ & ra & pr & صندلى (AT) \\
\hline$\Delta$ & $r$ & r & 1 & & & $\Delta$ & $\Delta M$ & توب (C) \\
\hline
\end{tabular}




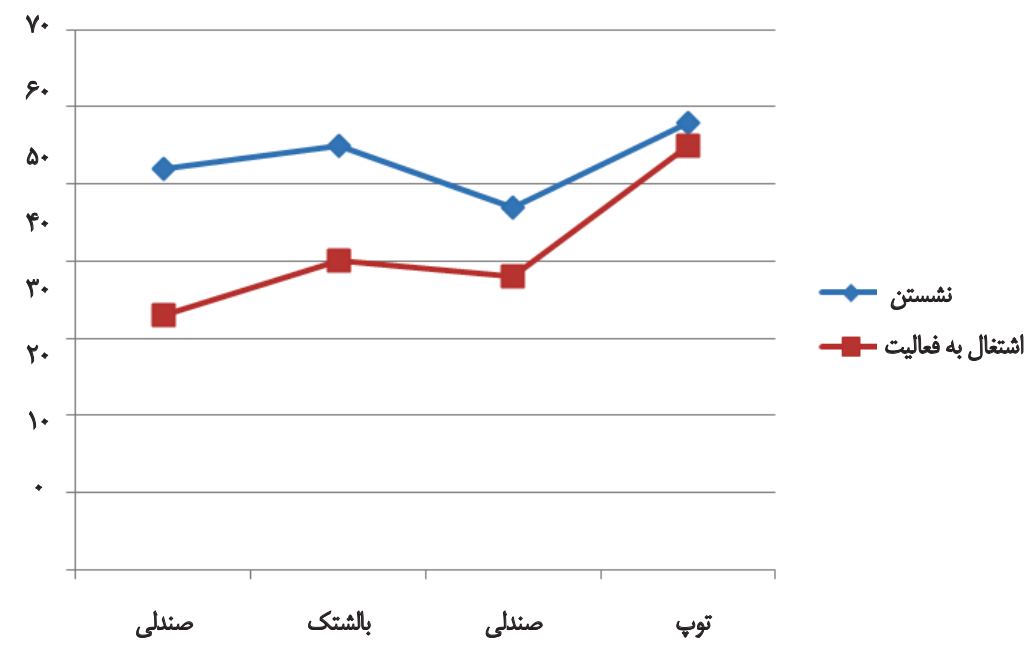

توانبخننى

تصوير با. روند تغييرات ميائكين دفعات نشستن و اشتغال به فعاليت دائشآموز دوم در مراحل مختلف تحقيق.

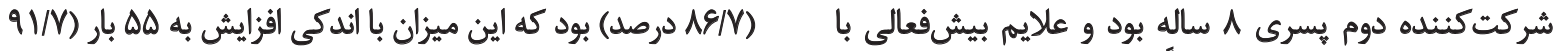

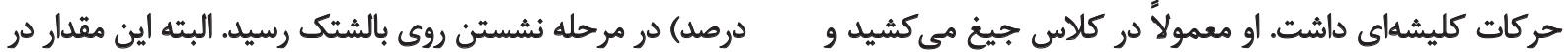

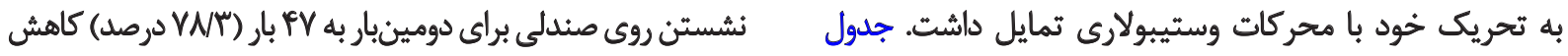

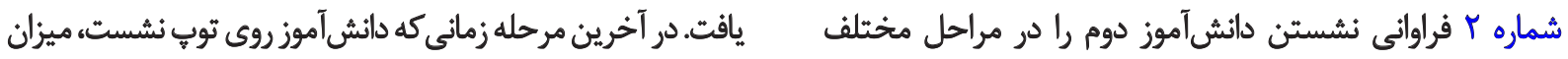

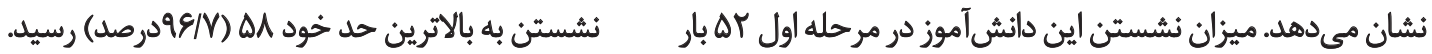

جدول ". ميزان نشستن، رفتار اشتغال و عدماشتغال به فعاليت دانش آموز سوم (بدوناشتغال به فعاليت يا فعاليت بدونهدف).

\begin{tabular}{|c|c|c|c|c|c|c|c|c|}
\hline ميزان كلي عدماشتثال به & موارد ديكّر & حركات كليشهايى & حُيره هشدن & هرثز هزن & بداهون هدفن & ميز فئن الشتغال & ميزَان نُشستن & ثوع صندلىي \\
\hline r. & & 8 & 1 & & ז" & r. & $\pi$ & صندلى (A) \\
\hline ra & & $r$ & M & 1 & $r$ & ra & $\Delta r$ & بالشتى (B) \\
\hline M & 1 & $r$ & r. & & 9 & ra & r & صندلى (AY) \\
\hline$r_{*}$ & 1 & $r$ & $r$ & & Ir & r. & $\pi$ & توب (C) \\
\hline
\end{tabular}

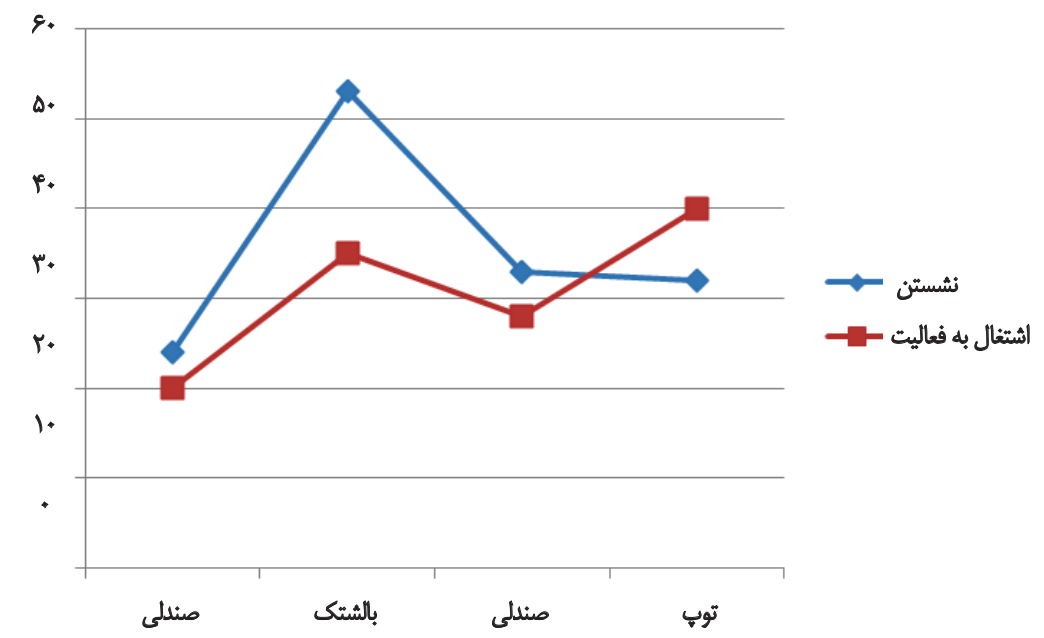

توانبخننى

تصوير "م. روند تغييرات ميانكين دفعات نشستن و اشتغال به فعاليت دانش آموز سوم در مراحل مختلف تحقيق. 
جدول F. ميزان نشستن، رفتار اشتغال و عدماشتغال به فعاليت دانشآموز حهارم (بدوناشتغال به فعاليت يا فعاليت بدونهدف).

\begin{tabular}{|c|c|c|c|c|c|c|c|c|}
\hline ميزان كلى عدماشتثال به & موارد ديكر & حركات كليشهاى & خيرهشبن & هرتزون & بدورنهدف & ميزان اشتثال & ميزان نشستن & نوع صندلى \\
\hline ir & r & & r & & $\checkmark$ & is & Q. & صندلى (A) \\
\hline r & 1 & & 1 & & & $\mathbb{M}$ & $\Delta q$ & بالشتّك (B) \\
\hline if & $\checkmark$ & & $\Delta$ & & r & re & pq & صندلى (AT) \\
\hline 1 & & & 1 & & & $\Delta q$ & 49 & توب (C) \\
\hline
\end{tabular}

توانبخنتى

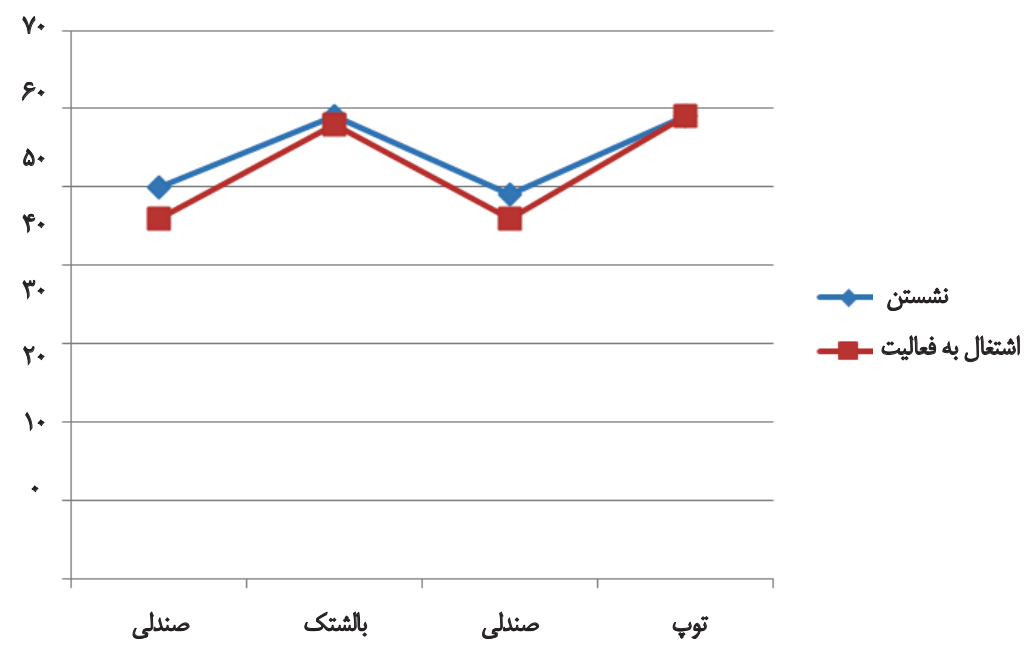

توانبخننى

تصوير أ. روند تغييرات ميانكين ففعات نشستن و اشتغال به فعاليت دانش آموز جهارم در مراحل مختلف تحقيق.

همان طور كه در جدول مذكور مشاهده مي شوده دانش آموز دوم روند اين تغييرات رانشان مي دهد.

شركت كننده سوم بسرى ^ ساله با مشكلات دركى بينايي،

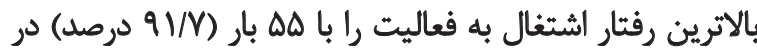

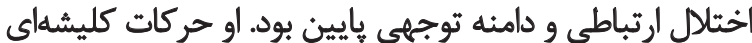

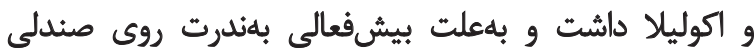

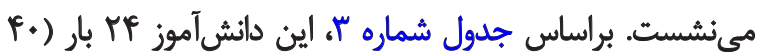

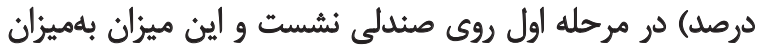

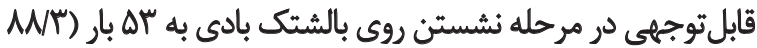

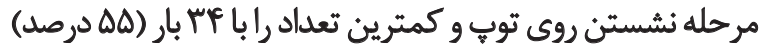

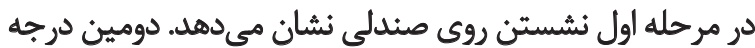

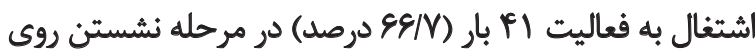

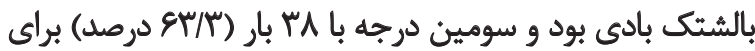

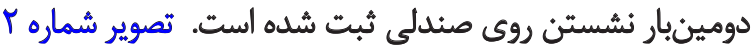

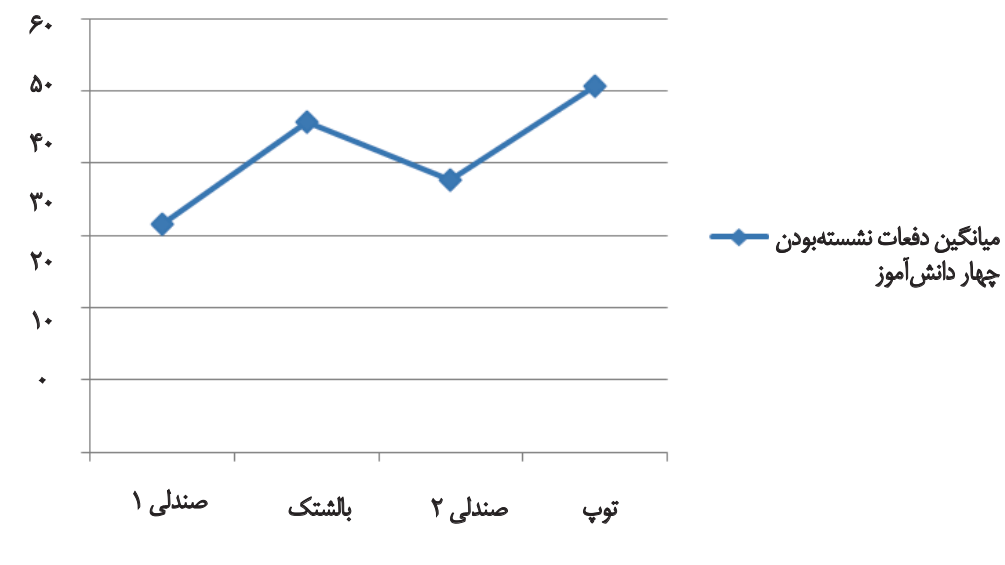

توانبخننى

تصوير ه. روند تغييرات ميانكين دفعات نشستن تمامى دانش آموزان در مراحل مختلف تحقيق. 


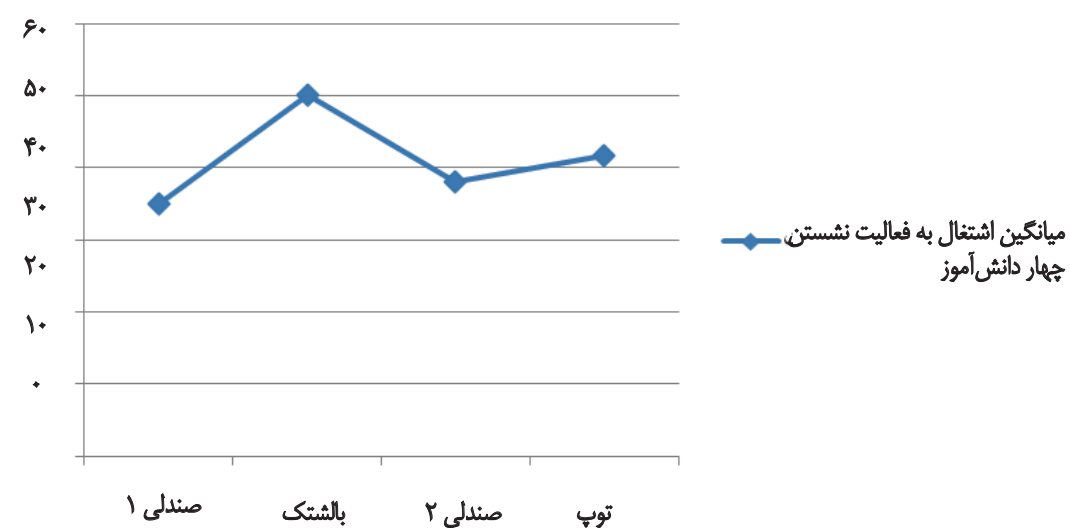

تصوير و. روند تغييرات ميانكّين اشتغال به فعاليت تمامى دانش آموزان در مراحل مختلف تحقيق.

مربوط به مرحله جهارم با 19 بار (9NT درصد) و دومين ميزان

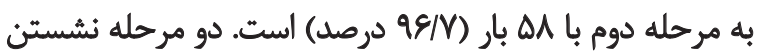

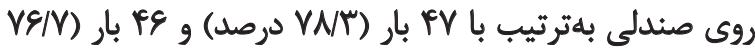

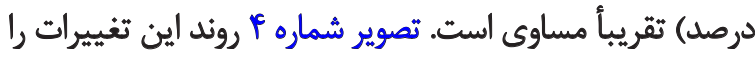

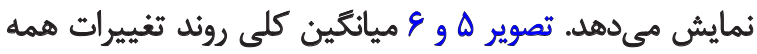

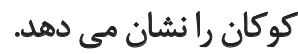

هطابق آزمون كارس، يافتهها نشان مي دهد توب مي تواند رفتيار هاي

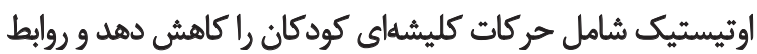

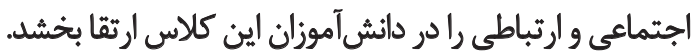

ثک

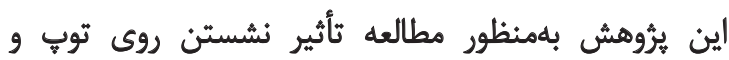

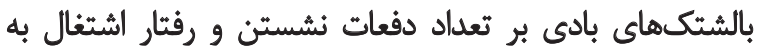
فعاليت كودكان مبتلا به اختالال طيف اوتيسم انجام شده است

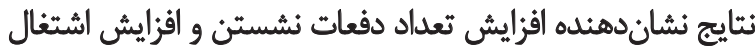

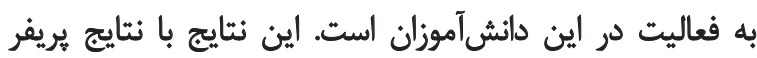

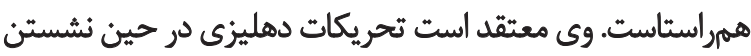

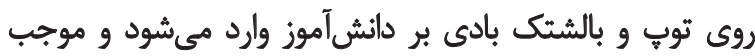

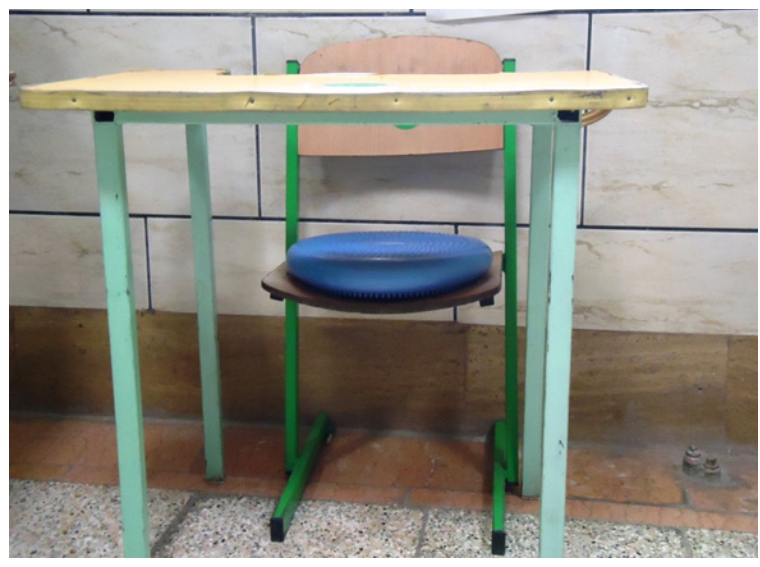
توانبخنتى تصوير لم بالشتئك بادى مورداستفاده در تحقيق.

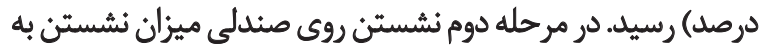

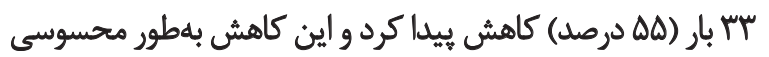

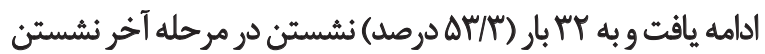

روى توب رسيد.

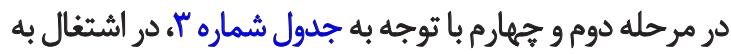

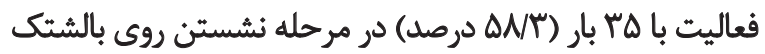

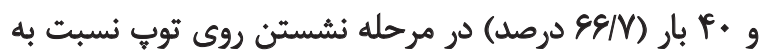

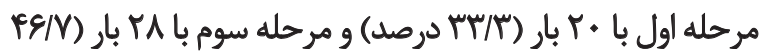
درصد) ييشرفت وجود دارد.

شركت كنئده جهارم يسرى || ساله با مشكلات شنيداري،

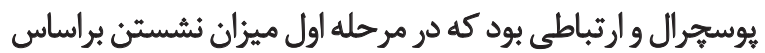

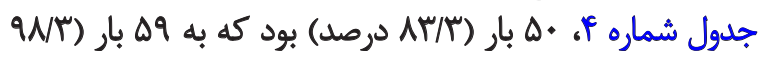

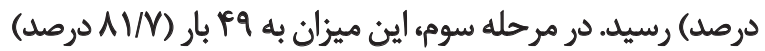

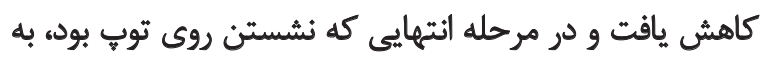

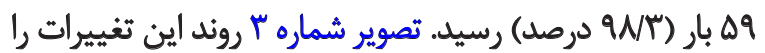
نمايش مى دهد. براساس جدول ذكرشده، بالاترين رفتار اشتغال به فعاليت

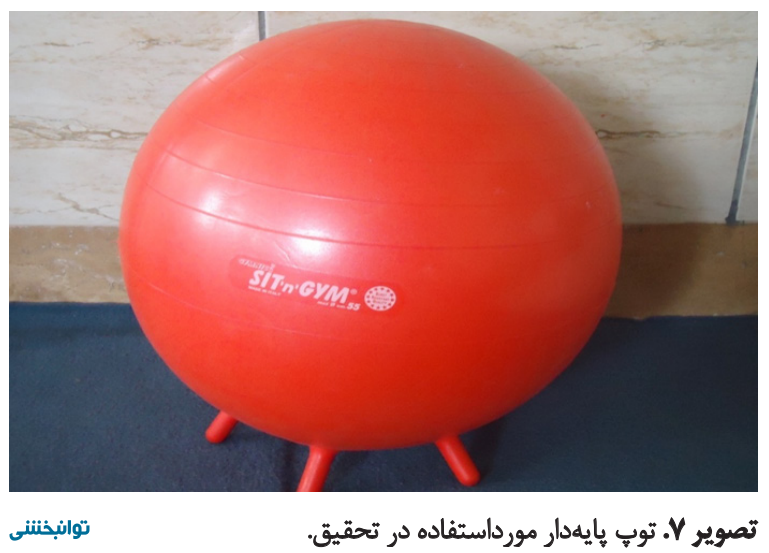


بود و نمىتوانست در محيط حياط بدود. تعادل دانش آموز سوم نيز نامناسب بود و تمايلى به تحريكات دهليزى شديد بديد نداشت.

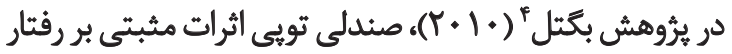

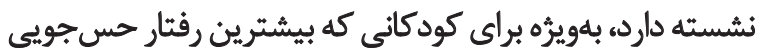

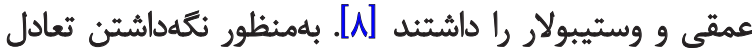

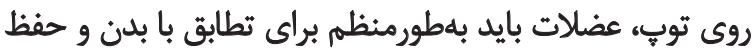

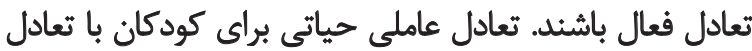

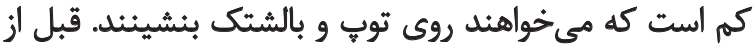

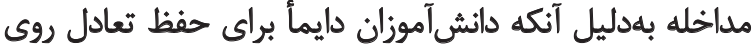

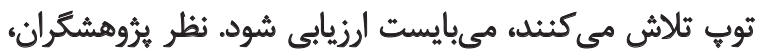

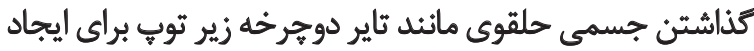

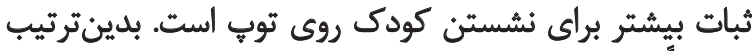

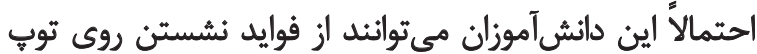
بهره بيشيترى برند.

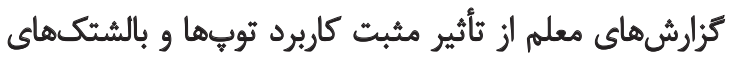

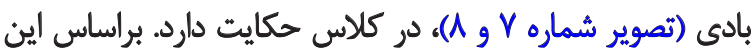

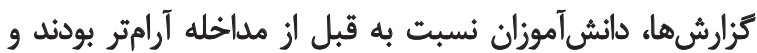

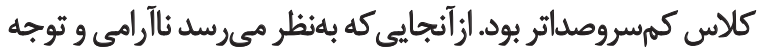

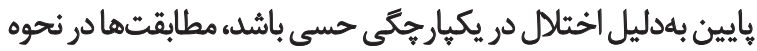

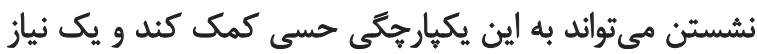

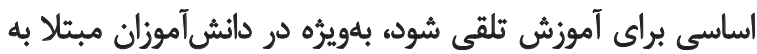
اختالال طيف اوتيسم كه در اين زمينه مشكل دارند [ـ ـ1].] كودك مبتلابهاختلال طيف اوتيسمر رفتارهاي تخريبي متنوعى

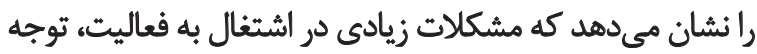

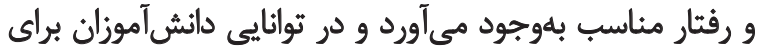

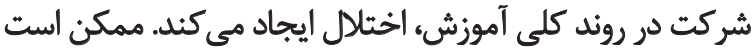

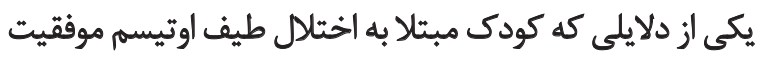

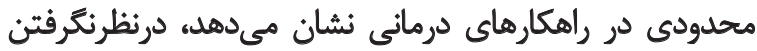

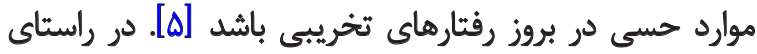

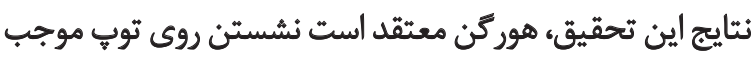

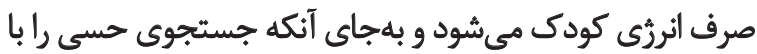

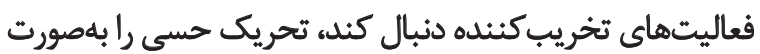

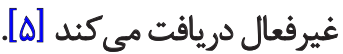
در مطالعهاى همراستا تونستول بيان كرد كاربرد توبدرمانى فيكي

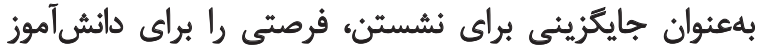

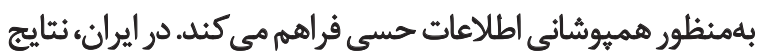

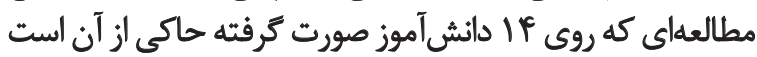

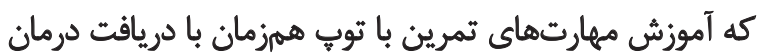

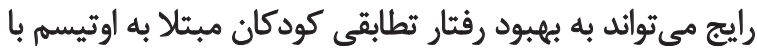

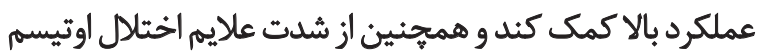

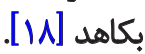

افزرايش سطح برانكيختكى و توجه بيشتر به فُعاليت مىشود [1/]].

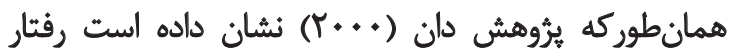

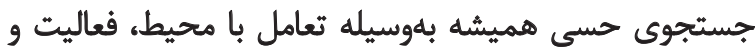

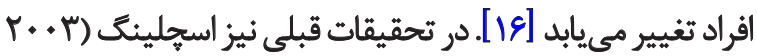

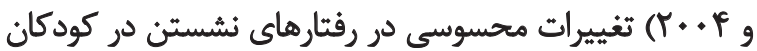

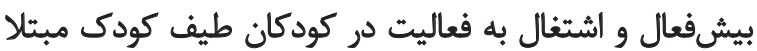

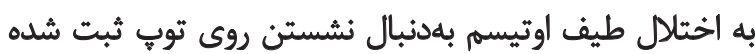
است. علاوهبراين فرض مىشود بالشتكنهاى بادى ديسكى شكل

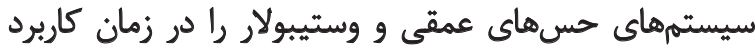

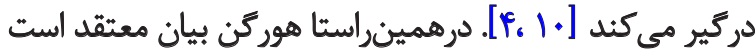

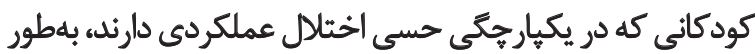

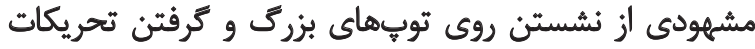
وستيبولار بهره مىبرند إه] .

كاهش عدماشتغال به فعاليت ثبتشده در نتايج مىتواند

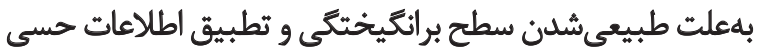

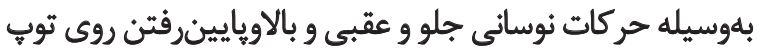

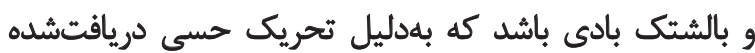

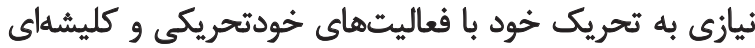

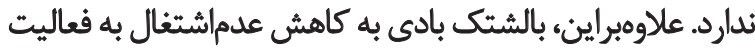

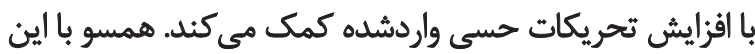

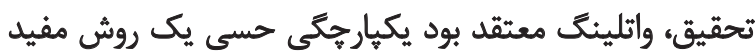

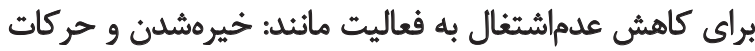

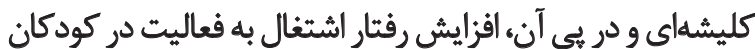

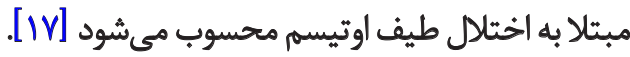

در همه جهار دانش آموز، اشتغال به فعاليت و در دو مورد (مورد

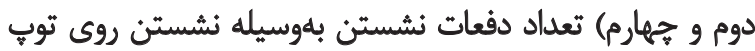

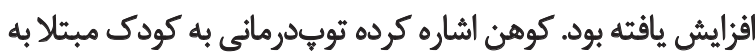

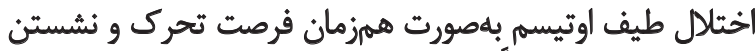

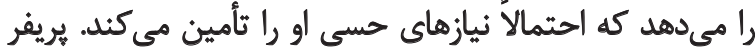

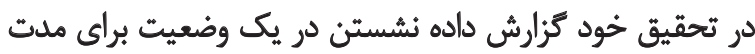

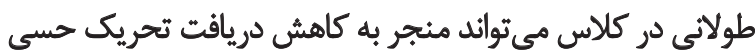

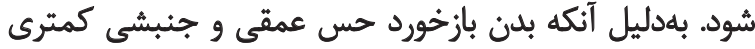

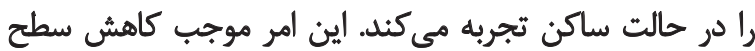

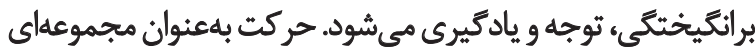

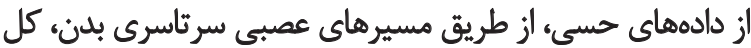

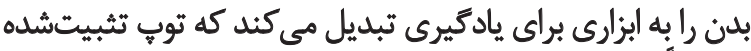

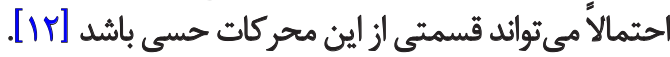

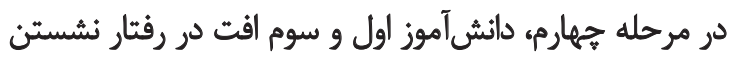
روى توب رانسبت به ديكر مراحل نشان دادند. اين كاهش مئ مي تواند

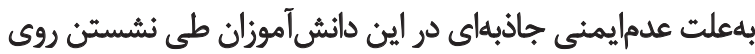

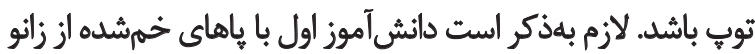

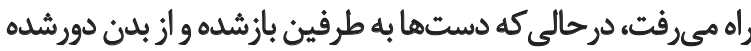




\section{References}

[1] American Psychiatric Association. Diagnostic and statistical manual of mental disorders (DSM-5). $5^{\text {th }}$ ed. Arlington, V.A.: American Psychiatric Association Publishing; 2014.

[2] Noack J, Richter K, Laube G, Haghgoo HA, Veh RW, Engelmann M. Different importance of the volatile and non-volatile fractions of an olfactory signature for individual social recognition in rats versus mice and short-term versus long-term memory. Neurobiology of Learning and Memory. 2010; 94(4):568-75.

[3] Haghgoo HA, Laube G, Engelmann M, Veh RW. The AOB subdivisions in rats respond differently to social stimulation. Social \& Behavioral Sciences. 2012; 32(1):411-20.

[4] Schilling DL, Schwartz IS. Alternative seating for young children with autism spectrum disorder: effects on classroom behavior. Journal of Autism \& Developmental Disorders. 2004; 34(4):42332.

[5] Koegel L, Matos-Fredeen R, Lang R, Koegel R. Interventions for children with autism spectrum disorders in inclusive school settings. Cognitive \& Behavioral Practice. 2011; 19:401-12.

[6] Ghanizadeh A. A preliminary study on screening prevalence of pervasive developmental disorder in schoolchildren in Iran. Journal of Autism and Developmental Disorders. 2008; 38(4):759-63.

[7] Samadi SA, McConkey R, Kelly G. Enhancing parental wellbeing and coping through a family-centred, short course for Iranian parents of children with an autism spectrum disorder. International Journal of Research \& Practice. 2013; 17(1):27-43.

[8] Bagatell N, Mirigliani G, Patterson C, Reyes Y, Test L. Effectiveness of therapy ball chairs on classroom participation in children with autism spectrum disorders. American Journal of Occupational Therapy. 2010; 64(6):895-903.

[9] Rajabi B, Pourmohamadreza Tajrishi M, Haghgoo, Vosuqi A, Biglarian A. [The effect of pivotal response training on Behavioral Problems of 4-6 years old children with autism (Persian)]. 2014; 14(1):50-58.

[10] Schilling DL, Washington K, Billingsley FF, Deitz J. Classroom seating for children with attention deficit hyperactivity disorder: therapy balls versus chairs. American Journal of Occupational Therapy. 2003; 57(5):534-41.

[11] Winkler, Charlotte A. The graduate school univel'sity of Wisconsin-Stout menomonie. Madison: University of Wisconsin; 2010.

[12] Pfeiffer B, Henry A, Miller S, Witherell S. Effectiveness of disc 'o'sit cushions on attention to task in second-grade students with attention difficulties. American Journal of Occupational Therapy. 2008; 62(3):81-274.

[13] Samadi SA, Mahmoodizadeh A, McConkey R. A national study of the prevalence of autism among five-year-old children in Iran. Autism. 2012; 16(1):5-14.

[14] Samadi SA, McConkey R. The utility of the Gilliam autism rating scale for identifying Iranian children with autism. Disability \& Rehabilitation. 2013;36(6):452-56.

[15] Ghamari Kivi H, Kianersi F, Nasoudi R, Agh AS, Mehrabadi $\mathrm{S}$. [The comparison of effectiveness of applied behavioral analysis and treatment-education approach on stereotyped behavior,
مطابق آزهون كارس توبه هي تواند رفتارهاي اوتيستيكي

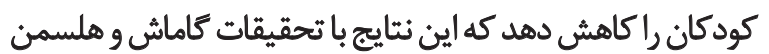

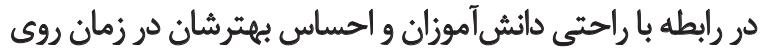

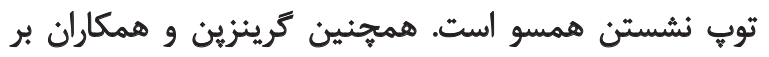
نقش تحريك حسى بر كاهش انزواي اجتماعى و عدمتوجيه به به

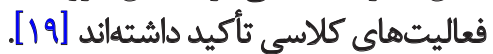

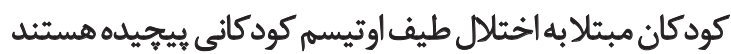

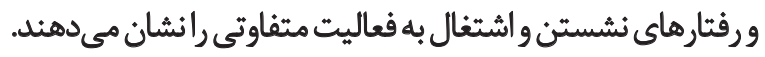

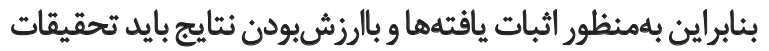

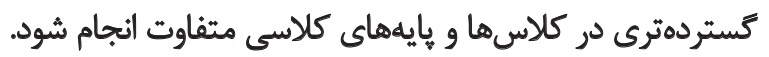

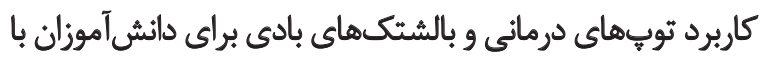

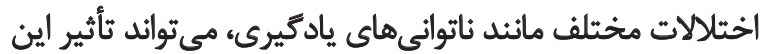

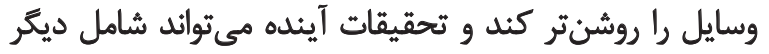

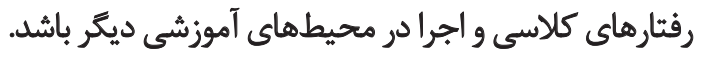
S. در اين تحقيق، توب و بالشتك بادى بر رفتار نشستن و ائتغال به

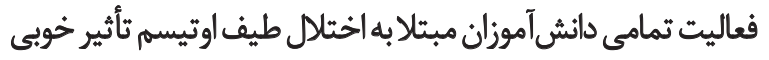

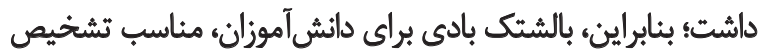

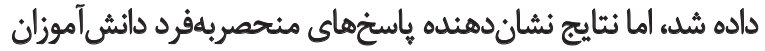

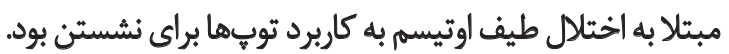
در تلاش براى ايجاد مدارس آموزشى فراكير براى داتشي آموزان

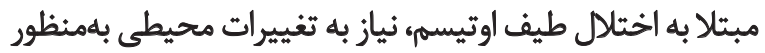

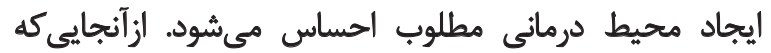

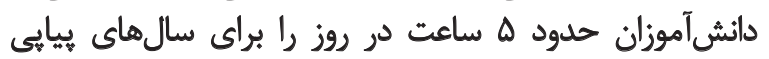

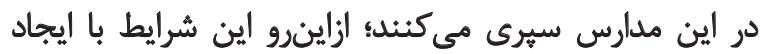

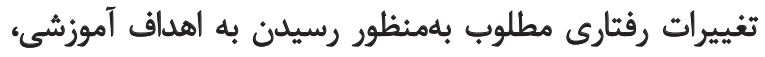

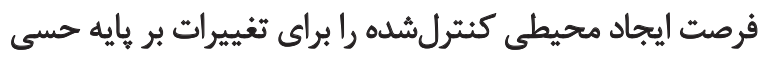

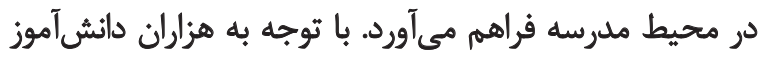

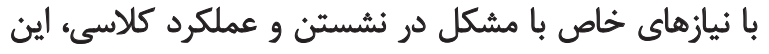

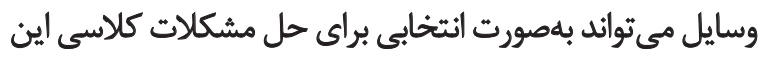

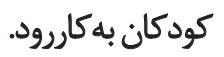

كودكان با اختلال طيف اوتيسمه كودكانى بيجيده هستند

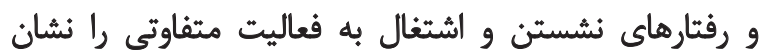

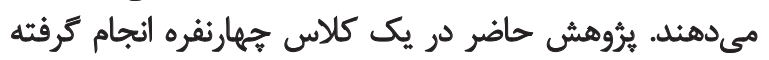

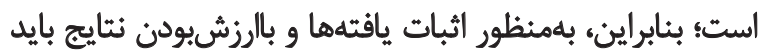

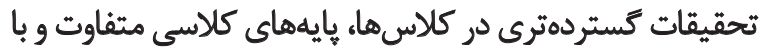

$$
\text { حجم نمونه بزركتئر صورت كيردي }
$$$$
\text { تشيكر و قدرداني }
$$

اين مقاله بركرفته از هاياننامه دكترى آقاى نادر متينصدر در دراني

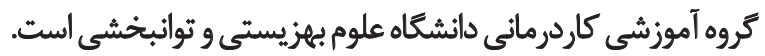


interactional and communicational problems in autistic children (Persian)]. Journal of Rehabilitation. 2012; 13(2):25-33.

[16] Dunn W. The sensations of everyday life: empirical, theoretical, and pragmatic considerations. American Journal of Occupational Therapy. 2001; 55(6):608-20.

[17] Watling RL, Dietz J. Immediate effect of Ayres's sensory integration-based occupational therapy intervention on children with autism spectrum disorders. American Journal of Occupational Therapy. 2007; 61(5):574-83.

[18] Jekan M, Hoseini SA, Mohammadi MR, Salehi M. [The effect of ball Skills training on adaptive behaviors of children with high functioning autism (Persian)]. Journal of Rehabilitation. 2013; 13(1):136-44.

[19] Greenspan SI, Wieder S. Developmental patterns and outcomes in infants and children with disorders in relating and communicating: a chart review of 200 cases of children with autistic spectrum diagnoses. Journal of Developmental and Learning Disorders. 1997; 1:87-142. 
